\title{
Pengaruh saluran distribusi offline dan online travel agent dan implikasinya terhadap revenue per available room di the anvaya beach resort bali
}

\author{
Made Deny Kharisma1), Putu Diah Sastri Pitanatri' ${ }^{2),}$ I Dewa Putu Hendri Pramana ${ }^{3)}$ \\ Administrasi Perhotelan, Politeknik Pariw isata Bali ${ }^{123)}$ \\ Telp/Fax: +62 361 773537, Email: info@ppb.ac.id \\ J1. Dharmaw angsa, Benoa, Kec. Kuta Sel., Kabupaten Badung, Bali 80361 \\ Email: denykharismamade@gmail.com
}

\begin{abstract}
Abstrak
Ketatnya persaingan yang terjadidan mulai terdis rupsinya pasar Offline TravelAgentoleh OnlineTravel Agent menuntut pihak manajemen hotel mempertimbangkan secara selektif saluran distribusimanayang harus dimaksimalkan guna meraih kinerja pendapatan kamar yang baik melalui Revenue per Available Room. Penelitian inibertujuan untuk mengetahui dan mengkaji bagaimana pengaruh penjualan kamar melalui s aluran distribsui Offline Travel Agent dan Online Travel Agent secara parsialmaupunsimultan terhadap Revenue per Available Room. Hasil penelitian secara parsial dan simultan menunjukanbahwa saluran distribusi Offline Travel Agent dan Online Travel Agent berpengaruh positif (searah) dan signifikan terhadap Revenue per Available Room (RevPar). Hasil analisis koefisien determinasi menunjukkan bahwa nilai $R^{2}$ para variabel saluran dis tribusi Offline Travel Agent sebesar 0,765ataujka diinterpretasikan sebesar 76,5\% dengan kontribusi yang kuat. Pada salurah distribusi Online Travel Agent nilai $\mathrm{R}^{2}$ sebes ar 0,836 atau sebesar $83,6 \%$ deng an kontribusi yang sangat kuat. Sementarasecara simultan nilai $\mathrm{R}^{2}$ sebesar 0,865 menunjukkan bahwa $86,5 \%$ variabel Revenue per AvailableRoomdapat dijelaskan melalui kedua variabel bebas tersebut, sedangkan sis anya sebes ar 13,5\% dijelaskan oleh variabel lain diluar variabel penelitian. Sebagai kesimpulannya saluran dis tribusi Offline Travel Agent dan Online Travel Agent memiliki pengaruh dan kontribusiterhadap Revenue per Available Room, namun pengaruh dan kontribusi lebih besar dihasilkan oleh saluran distribusi Online Travel Agent.
\end{abstract}

Kata kunci: Saluran Distribusi, Offline Travel Agent, Online Travel Agent, dan Revenue perAvailable Room.

\begin{abstract}
The competition that occurs and the disruption of the Offline Travel Agent market by Online Travel Agents demanding the hotel management to consider selectively which distributionchannelsshouldbe maximized in order to achieve good room revenue performance through RevenueperAvailableRoom. This study aims to find out and examine how the influence of room sales through Offline TravelAgent and Online Travel Agent distribution channels partially or simultaneously to RevenueperAvailable Room (RevPar). The results of the partial and simultaneous research show thattheOfflineTravelAgent and Online Travel Agent distribution channels have a positive (unidirectional)andsignificanteffecton Revenue per Available Room. The results of the coefficient of determination analysis show that the $R^{2}$ value of the Offline Travel Agent distribution channel variable is 0.765 or ifinterpretedat $76.5 \%$ with a strong contribution. On the line of Online Travel Agent distribution $R^{2}$ value is 0.836 or $83.6 \%$ with a very strong contribution. While simultaneously the $R^{2}$ value of 0.865 shows that $86.5 \%$ ofthe Revenue variable per Available Room can be explained through the two independent variables, while the remaining $13.5 \%$ is explained by other variables outside the research variable. In conclusion, Offline Travel Agent and Online Travel Agent distribution channels have influenceand contributiontoRevenue per Available Room, but greater influence and contribution is generated by the Online TravelAgent distribution channel.
\end{abstract}

Keywords: Distribution Channels, Offline Travel Agent, Online Travel Agent, and Revenue per Available Room. 


\section{PENDAHULUAN}

Dalam dunia perhotelan, era digital ini digunakan sebagai sarana pemasaran dan promosi oleh manajemen. Berbeda dengan satu dekade terakhir bisnis online dimana hotel-hotel mengambil pasar baw ah (low-end) karena belum adanya media penunjang dan platform yang digunakan, yang kemudian dengan seiring berjalannya waktu dan jaman bisnis hotel melalui online atau sering disebut e-commerce ini semakin membaik dan mulai bergerak masuk ke pasar atas (high-end) hal ini disebut market disruption (Lieber, E., \& Syverson, C., 2012). Di Indonesia sendiri perkembangan ini telah banyak diulas peneliti, diantaranya Pitana \& Pitanatri $(2016,2019)$ yang mengkaji pentingnya menjadi pemasar yang digital native dalam era disruption seperti saat ini. Apalagi $e$ commerce spend di Indonesia terbesar ada pada kategori travel dengan angka \$ 9.376 billion atau sekitar 133 triliun rupiah (Hootsuite Indonesia Digital Landscape, 2019). Oleh sebab itu, maka pemasaran produk dan jasa yang dimiliki kini lebih mudah karena adanya platform atau saluran distribusi yang memanfaatkan perkembangan teknologi.

Dalam melakukan penjualan suatu produk, salah satu elemen yang berperan penting adalah saluran distribusi (distribution channel), selama ini digunakan untuk mengantarkan produk ke tangan konsumen. Yoeti (2003) menjelaskan bahwa saluran distribusi digunakan untuk menyalurkan produk yang dimiliki. Perusahaan bisa memilih cara penyaluran barang atau jasa yang dapat dilakukan secara langsung (direct booking) dan secara tidak langsung (indirect booking).

Direct booking dapat dilakukan melalui berbagai cara yaitu dengan dapat langsung menghubungi pihak hotel untuk melakukan pemesanan kamar baik melalui telepon, fax, email, ataupun langsung datang ke hotel untuk melakukan pemesanan kamar (walk in guest), dan dapat melakukan pemesanan kamar melalui official website (Liu, J. N., \& Zhang, E. Y., 2014). Indirect Booking atau reservasi secara tidak langsung adalah suatu pemesanan kamar yang dilakukan melalui suatu perantara atau perusahaan lain (Masiero, L., \& Law, R., 2016). Law et al. (2013) juga menyebutkan bahwa pemesanan kamar dengan indirect booking dapat melalui beberapa perantara yaitu Offline Travel Agent, Online Travel Agent dan Global Distribution System.

The Anvaya Beach Resort Bali merupakan salah satu hotel bintang lima yang terletak di Jalan Kartika, Tuban, Kuta, Kabupaten Badung yang menggunakan saluran distribusi baik secara direct booking maupun indirect booking. Berdasarkan hasil wawancara yang dilakukan dengan $E$ Commerce Manager, pada saluran distribusi direct booking pendapatan kamar dipengaruhi oleh FIT (Free Individual Traveller) yaitu melalui berbagai cara seperti telepon, email, official hotel website dan walk-in, sementara pada saluran distribusi indirect booking pendapatan kamar dipengaruhi oleh online travel agent, offline travel agent dan Global Distribution System (GDS). Pihak E-Commerce Manager juga menyatakan pendapatan kamar dipengaruhi sumber - sumber reservasi lainnya atau market segment, seperti reservasi yang berasal dari corporate, package, meeting, government, unique, adhoc dan Group - IT series.

Menurut Warren dalam (Budiasa, 2014) banyak cara yang dapat dilakukan hotel untuk memaksimalkan pendapatan kamar, salah satunya dengan memasarkan dan menjual produknya melalui saluran distribusi. Dalam mencapai target pendapatan, hotel tidak selalu mampu mencapai budget atau target yang diinginkan (Steed, E., \& Gu, Z., 2009). Untuk mampu mencapai target pendapatan yang ditentukan, sales \& marketing department harus lebih selektif lagi dalam memilih dan memanfaatkan potensi saluran distribusi yang tepat untuk meningkatkan pendapatan kamar.

Berhubungan dengan pencapaian target penjualan yang telah ditentukan, banyak faktorfaktor yang dijadikan pertimbangan dalam menilai performa pendapatan kamar selain hotel sudah mencapai target pendapatan kamar salah satunya adalah melihat pada performa RevPAR (Revenue per Available Room) (Santoro, G., 2015). Revenue per Available Room atau pendapatan per jumlah kamar yang tersedia adalah hasil perhitungan keseluruhan pendapatan penjualan kamar dalam 
periode tertentu dibagi dengan jumlah kamar tersedia dalam periode tertentu yang merupakan salah satu key performance indicator $(K P I)$ atau indikator dalam penilaian kinerja yang digunakan oleh industri perhotelan untuk menilai kinerja keuangan dan bisnis (Santoro, G., 2015). RevPar berfungsi sebagai metrik atau ukuran yang berkaitan dengan pendapatan kamar, tingkat hunian kamar dan harga rata-rata kamar yang menjadikannya indikator penting dari kinerja pendapatan kamar serta komponen penting untuk revenue management strategy (Schwartz et al, 2017). E-Commerce Manager menyatakan Peningkatan dan penurunan Revenue per Available Room berbanding lurus dengan pendapatan kamar, jadi apabila pendapatan kamar meningkat dan mencapai target maka Revenue per Available Room juga akan meningkat dan sesuai dengan target apabila total kamaryang dijual sama. E-Commerce Manager juga menambahkan bahwa peningkatan dan penuruan pendapatan kamar dipengaruhi oleh setiap saluran distribusinya dan sumber-sumber reservasinya.

Melihat dari fenomena tersebut saluran distribusi Offline Travel Agent dan Online Travel Agent mempengaruhi tingkat penjualan kamar dan pendapatan kamar, namun pengaruhnya terhadap Revenue per Available Room sebagai salah satu indikator penilaian kinerja pendapatan yang ada di The Anvaya Beach Resort Bali belum dapat diketahui dan saluran distribusi mana yang lebih berpengaruh dan berkontribusi dari masing-masing saluran distribusi tersebut belum mampu dimaksimalkan. Maka perlu dilakukan penelitian lebih lanjut untuk mengetahui bagaimanakah pengaruh saluran distribusi Offline travel agent dan Online travel agent terhadap Revenue per Available Room di The Anvaya Beach Resort Bali.

\section{METODE PENELITIAN}

Penelitian ini digolongkan ke dalam penelitian asosiatif (pengaruh) yaitu meneliti pengaruh saluran distribusi offline travel agent dan online travel agent terhadap revenue per available room. Objek penelitian dibatasi hanya pada saluran distribusi offline travel agent dan online travel agent. Penelitian ini dilakukan pada sales and marketing department di The Anvaya Beach Resort Bali. Dengan jenis kualitatif yang bersumber premier diperoleh melalui hasil wawancara dan observasi dengan E-Commerce Manager dan data kuantitaif yang bersumber sekunder diperoleh melalui studi dokumentasi. Pada penelitian ini teknik analis data yang digunakan adalah Teknik analisis data kuantitatif.

Analisis deskriptif kuantitatif menggunakan statistik sebagai alat analisis data, statistik ini diartikan sebagai metode pengetahuan yang berhubungan dengan cara - cara penafsiran dan penarikan kesimpulan berdasarkan kumpulan data yang telah diperoleh sebelumnya melalui proses observasi dan penganalisaan yang dilakukan melalui aturan - aturan dan prosedur - prosedur tertentu. (Silalahi, 2006).

Dalam penelitian ini digunakan perangkat lunak SPSS Versi 24.0 (Statistic Product \& Service Solution) untuk membantu mengolah data. Teknik analisis data yang pertama adalah analisis regresi linier berganda. Menurut Riduw an (2011) analisis regresi berganda adalah alat analisis peramalan nilai pengaruh dua variabel bebas atau lebih terhadap satu variabel terikat untuk membuktikan ada atau tidaknya hubungan fungsi atau hubungan kasual antara dua variabel bebas atau lebih dengan satu variabel terikat. Kemudian Uji T digunakan untuk menguji signifikansi hubungan antara kedua variabel secara terpisah atau parsial (Ghozali, 2011), uji ini digunakan untuk mengetahui apakah variabel offline travel agent dan online travel agent benar - benar berpengaruh terhadap revenue per available room secara parsial. Secara simultan digunakan Uji F untuk mengetahui tingkat signifikansi pengaruh variabel - variabel bebas secara bersama - sama (simultan) terhadap variabel terikat (Gozali, 2011). Uji ini digunakan untuk mengetahui apakah variabel offline travel agent dan online travel agent benar - benar berpengaruh terhadap revenue per available room secara simultan. Untuk mengetahui kontribusinya digunakan Uji Koefisien Determinasi (Algifari, 2009). Koefisien determinasi digunakan untuk mengetahui persentase pengaruh variabel offline travel agent dan online travel agent terhadap revenue per available room. 
Hal ini bertujuan untuk mengetahui besarnya kontribusi variabel saluran distribusi offline travel agent dan online travel agent terhadap revenue per available room dilihat melalui nilai koefisiennya $\left(\mathrm{r}^{2}\right)$. Hasil pengolahan data yang diperoleh dalam penelitian ini akan didukung dengan hipotesis yang akan menjawab rumusan masalah penelitian ini.

\section{HASIL DAN PEMBAHASAN}

Berdasarkan Tabel 1 dibawah ini hasil uji regresi linier berganda dapat dilihat nilai konstanta sebesar 224.670,167 dan koefisien untuk Offline Travel Agent $\left(\mathrm{X}_{1}\right)$ 59,380, koefisien untuk Online Travel Agent $\left(\mathrm{X}_{2}\right)$ 122,387. Dari tabel diatas dapat dibuat model regresinya yakni $\mathrm{Y}=$ 224.670,167 + 59,380X1 + 122,387X2. Sehingga dapat dikatakan pengaruh Online Travel Agent dengan jumlah peningkatan Rp. 122,387 per satu satuan lebih besar dibandingkan Offline Travel Agent dengan jumlah Rp. 59,380 per satu satuan. Dapat dilihat juga apabila The Anvaya Beach Resort Bali tidak menerapkan saluran distribusi melalui Offline Travel Agent dan Online Travel Agent maka Revenue per Available Room sebesar Rp. 224.670,167.

Nilai thitung untuk variabel $\mathrm{X}_{1}$ (Offline Travel Agent) 2,274> 2,059 lebih besar dari $\mathrm{t}_{\text {tabel }}$ dan nilai signifikan adalah $0,032<0,05$, sehingga dapat disimpulkan $\mathrm{X}_{1}$ (Offline Travel Agent) secara parsial berpengaruh terhadap Y (Revenue per Available Room). Nilai thitung 2,274 berada di daerah penolakan Ho yang artinya Ho ditolak dan Ha diterima, maka dapat disimpulkan bahwa penjualan kamar melalui Offline Travel Agent berpengaruh signifikan dan berhubungan positif (searah) terhadap Revenue per Available Room di The Anvaya Beach Resort Bali.

Tabel 1. Hasil Uji Regresi Berganda $X_{1}$ dan $X_{2}$ terhadap Y

\section{Coefficients $^{\mathrm{a}}$}

Model

Unstandardized

Coefficients

B

1

(Constant)

224670.167

59.380

122.387

Online
28.990

Std. Error

43837.538

26.114

.336

.624

Beta
Standardized $\mathrm{T}$

Coefficients

$\begin{array}{lll} & 5.125 & .000 \\ .336 & 2.274 & .032 \\ .624 & 4.222 & .000\end{array}$

a. Dependent Variable: RevPAR

Sumber: Hasil Pengolahan Data SPSS 24, 2019

Nilai thitung untuk variabel $\mathrm{X}_{2}$ (Online Travel Agent) 4,222> 2,059 lebih besar dari tabel dan nilai signifikan adalah $0,000<0,05$, sehingga dapat disimpulkan $\mathrm{X}_{2}$ (Online Travel Agent) secara parsial berpengaruh terhadap Y (Revenue per Available Room). Nilai thitung 4,222 berada di daerah penolakan Ho yang artinya Ho ditolak dan Ha diterima, maka dapat disimpulkan bahwa penjualan kamar melalui Online Travel Agent berpengaruh signifikan dan berhubungan positif (searah) terhadap Revenue per Available Room di The Anvaya Beach Resort Bali.

Tabel 2. Hasil Analisis Uji F

ANOVA $^{\mathrm{a}}$

$\begin{array}{lllllll}\text { Model } & & \text { Sum of Squares } & \text { Df } & \text { Mean Square } & \text { F } & \text { Sig. } \\ 1 & \text { Regression } & 1586617665000.0 & 2 & 793308832700.00 & 76.83 & .000^{\mathrm{b}} \\ & 00 & & 0 & 4 & \end{array}$




$\begin{array}{llll}\text { Residual } & 247800336100.00 & 24 & 10325014000.000 \\ & 0 & & \\ \text { Total } & 1834418002000.0 & 26 & \\ & 00 & & \end{array}$

a. Dependent Variable: RevPAR

b. Predictors: (Constant), Online, Offline

Sumber: Hasil Pengolahan Data, 2019

Berdasarkan Tabel 2 diatas diperoleh nilai $\mathrm{F}_{\text {hitung }}$ sebesar 76,834 dimana nilai ini lebih besar dibandingkan dengan $\mathrm{F}_{\text {tabel }}$ sebesar 3,40 atau berada di daerah penolakan Ho. Dengan demikian hasil pengujian menunjukkan bahwa nilai tersebut menolak daerah penerimaan hipotesis nol (Ho) dan menerima hipotesis alternatif (Ha) artinya secara simultan dapat disimpulkan bahwa ada pengaruh yang signifikan antara variabel Offline Travel Agent $\left(\mathrm{X}_{1}\right)$ dan Online Travel Agent $\left(\mathrm{X}_{2}\right)$ terhadap Revenue Per Available Room (Y) di The Anvaya Beach Resort Bali.

Tabel 3. Hasil Analisis Koefisien Determinasi Offline Travel Agent

\section{Model Summary}

$\begin{array}{lllll}\text { Model } & \text { R } & \text { R Square } & \begin{array}{l}\text { Adjusted R } \\ \text { Square }\end{array} & \text { Std. Error of the Estimate } \\ 1 & .874^{\mathrm{a}} & .765 & .755 & 131425.48940\end{array}$

a. Predictors: (Constant), Offline

Sumber: Hasil Pengolahan Data SPSS 24, 2019

Berdasarkan Tabel 3 dapat dilihat nilai dari koefisien determinasi yakni 0,765 yang berarti besarnya pengaruh $\mathrm{X}_{1}$ terhadap $\mathrm{Y}$ adalah $76,5 \%$. Dapat diartikan bahwa 76,5\% Revenue per Available Room bisa dijelaskan oleh variabel bebas Offline Travel Agent sedangkan sisanya 23,5\% dijelaskan oleh faktor - faktor lain. Berdasarkan pedoman interpretasi koefisien determinasi diketahui bahw a koefisien determinasi varibel $X_{1}$ sebesar 76,5\% berada pada interval 60\% - 79,9\% yang dapat diartikan bahw a penjualan kamar melalui Offline Travel agent memiliki kontribusi yang kuat secara parsial terhadap Revenue per Available Room di The Anvaya Beach Resort Bali.

Tabel 4. Hasil Analisis Koefisien Determinasi Online Travel Agent

\section{Model Summary}

\begin{tabular}{lllll} 
Model & R & R Square & $\begin{array}{l}\text { Adjusted R } \\
\text { Square }\end{array}$ & $\begin{array}{l}\text { Std. Error of the } \\
\text { Estimate }\end{array}$ \\
1 & $.914^{\mathrm{a}}$ & .836 & .829 & 109760.90740 \\
\multicolumn{3}{l}{ a. Predictors: (Constant), Online }
\end{tabular}

Sumber: Hasil Pengolahan Data SPSS 24, 2019

Berdasarkan Tabel 4 dapat dilihat nilai dari koefisien determinasi yakni 0,836 yang berarti besarnya pengaruh $\mathrm{X}_{2}$ terhadap $\mathrm{Y}$ adalah $83,6 \%$. Dapat diartikan bahwa 83,6\% Revenue per Available Room bisa dijelaskan oleh variabel bebas Online Travel Agent sedangkan sisanya 16,4\% dijelaskan oleh faktor - faktor lain. Berdasarkan pedoman interpretasi koefisien determinasi diketahui bahw a koefisien determinasi varibel $\mathrm{X}_{2}$ sebesar $83,6 \%$ berada pada interval $80 \%-100 \%$ 
yang dapat diartikan bahw a penjualan kamar melalui Offline Travel Agent memiliki kontribusi yang sangat kuat secara parsial terhadap Revenue per Available Room di The Anvaya Beach Resort Bali.

Tabel 5. Hasil Analisis Koefisien Determinasi

\section{Offline Travel Agent dan Online Travel Agent}

\section{Model Summary}

\begin{tabular}{lllll} 
Model & $\mathrm{R}$ & $\mathrm{R}$ Square & $\begin{array}{l}\text { Adjusted R } \\
\text { Square }\end{array}$ & $\begin{array}{l}\text { Std. Error of the } \\
\text { Estimate }\end{array}$ \\
1 & $.930^{\mathrm{a}}$ & .865 & .854 & 101612.07610 \\
\multicolumn{4}{l}{ a. Predictors: (Constant), Online, Offline }
\end{tabular}

Sumber: Hasil Pengolahan Data SPSS 24, 2019

Berdasarkan Tabel 5, dapat dilihat nilai dari koefisien determinasi yakni 0,865 bahwa pengaruh penjualan kamar melalui Offline Travel Agent dan Online Travel Agent secara bersamaan atau simultan terhadap Revenue per Available Room di The Anvaya Beach Resort Bali adalah sebesar $86,5 \%$ terletak di interval $80 \%$ - 100\% yang artinya setiap kontribusi yang disumbangkan oleh Offline Travel Agent dan Online Travel Agent berpengaruh sangat kuat terhadap Revenue per Available Room. Sementara sisanya sebesar 13,5 \% dipengaruhi oleh faktor - faktor lain.

Dapat disimpulkan saluran distribusi Online Travel Agent memberi kontribusi yang lebih kuat daripada saluran distribusi melalui Offline Travel Agent dilihat dari hasil uji koefisieen determinasi pada Tabel 3 dan Tabel 4 dimana koefisien determinasi Offline Travel Agent sebesar 0,765 lebih kecil daripada koefisien determinasi pada Online Travel Agent koefisien determinasinya sebesar 0,836 dan interpretasi koefisien determinasi juga menyatakan bahwa kontribusi Online Travel Agent sangat kuat dibandingkan Offline Travel Agent dengan interpretasi koefisien determinasi yang kuat.

\section{KESIMPULAN}

Dari paparan anlisis diatas, maka disimpulkan saluran distribusi offline travel agent $\left(\mathrm{X}_{1}\right)$ berpengaruh signifikan secara parsial terhadap revenue per available room di The Anvaya Beach Resort Bali. Hal ini dibuktikan dengan nilai $\mathrm{T}_{\text {hitung }}$ pada variabel saluran distribusi offline travel agent sebesar 2,274 lebih besar dari $\mathrm{T}_{\text {tabel }} 2,059$ dengan nilai signifikan 0,032 $<0,05$ dan berada pada penolakan Ho. Saluran distribusi online travel agent $\left(\mathrm{X}_{2}\right)$ berpengaruh signifikan sec ara parsial terhadap revenue per available room di The Anvaya Beach Resort Bali. Hal ini dibuktikan dengan nilai $\mathrm{T}_{\text {hitung }}$ pada variabel saluran distribusi online travel agent sebesar 4,222 lebih besar dari $\mathrm{T}_{\text {tabel }}$ 2,059 dengan nilai signifikan $0,00<0,05$ dan berada pada penolakan Ho.

Secara simultan saluran distribusi offline travel agent dan online travel agent berpengaruh secara signifikan. Hal ini dibuktikan dengan nilai $\mathrm{F}_{\text {hitung }}$ sebesar 76,834 lebih besar dari nilai $\mathrm{F}_{\text {tabel }} 3,40$ dengan nilai signifikansi $0,00<0,05$ dan berada pada di daerah penolakan Ho. Besarnya pengaruh saluran distribusi offline travel agent $\left(\mathrm{X}_{1}\right)$ terhadap revenue per available room $(\mathrm{Y})$ dari hasil uji koefisien determinasi yang menunjukkan bahwa variabel offline travel agent $\left(\mathrm{X}_{1}\right)$ memberikan kontribusi terhadap revenue per available room (Y) sebesar 76,5\% dengan interpretasi pengaruh yang kuat.

Besarnya pengaruh saluran distribusi online travel agent $\left(\mathrm{X}_{2}\right)$ terhadap revenue per available room $(\mathrm{Y})$ dari hasi uji koefisien determinasi yang menunjukkan bahwa variabel online travel agent $\left(\mathrm{X}_{2}\right)$ memberikan kontribusi terhadap revenue per available room $(\mathrm{Y})$ sebesar 83,6\% dengan interpretasi pengaruh yang sangat kuat. Secara simultan dari hasil uji koefisien determinasi 
saluran distribusi offline travel agent $\left(\mathrm{X}_{1}\right)$ dan online travel agent $\left(\mathrm{X}_{2}\right)$ memiliki kontribusi sebesar 86,5\% dengan interpretasi pengaruh yang sangat kuat. Dapat disimpulkan berdasarkan hasil penelitian yang telah dilakukan saluran distribusi online travel agent $\left(\mathrm{X}_{2}\right)$ memiliki pengaruh dan kontribusi yang lebih kuat terhadap revenue per available room (Y) daripada saluran distribusi offline travel agent $\left(\mathrm{X}_{1}\right)$.

Saran yang dapat diberikan pada penelitian ini sebagai bahan pertimbangan bagi pihak manajemen hotel The Anvaya Beach Resort Bali dalam mengoptimalkan dan meningkatkan Revenue per Available Room adalah Memaksimalkan saluran distribusi Direct Booking (Scaglione et al., 2009) melalui pembaharuan Website users-interface beserta penjelasan secara detail mengenai kamar, fasilitas, pelayanan, paket - paket yang ditawarkan dan juga dengan cara menambahkan room inventory pada Website menggunakan metode dynamic pricing sesuai dengan periode waktu, demand, trend dan pertimbangan lainnya. Menerapkan sistem add-on pada hotel website (Chang et al., 2014). Pihak manajemen hotel khususnya e-commerce bekerjasama dengan pihak pengelola untuk menerapkan sistem add-on. Sistem add-on disini berupa fitur penambahan layanan seperti airport transfer, spa, $F \& B$ package, room upgrade dan promosi menarik lainnya yang dapat meningkatkan Revenue per Available Room. Meminimalisir selisih harga antara Online Travel Agent dengan harga Offline Travel Agent dapat menutupi rendahnya Revenue per Available Room (Mun, W., \& Hall, M. J., 2008). Memperhatikan online reviews yang diberikan oleh tamu. Minat untuk menginap tamu sangat dipengaruhi oleh reviews yang diberikan pada OTA atau situs resmi khusus review seperti TripAdvisor (Tuominen, 2011). Menjaga hubungan baik juga penting dilakukan kepada reviewers, seperti mengucapkan terima kasih karena telah mempercayakan hotelnya sebagai akomodasinya berlibur dan merespon dengan memberikan service recovery apabila terjadi keluhan untuk menunjukan bahwa pihak hotel berkomitmen dalam memberikan pelayanan yang maksimal (Ong, B. S., 2012).

\section{DAFTAR PUSTAKA}

Algifari. 2009. Analisis Statistik untuk Bisnis dengan Regresi, Korelasi, dan Nonparametrik. Edisi Pertama. Yogyakarta: BPFE.

Budiasa, I Gst Ngurah Putu \& Putu Diah Sastri Pitanatri. 2014. Manajemen Pemasaran. Badung: STP Nusa Dua Bali.

Chang, K. C., Kuo, N. T., Hsu, C. L., \& Cheng, Y. S. (2014). The impact of website quality and perceived trust on customer purchase intention in the hotel sector: website brand and perceived value as moderators. International Journal of Innovation, Management and Technology, 5(4), 255.

Digital 2019: Indonesia. 2019. https://datareportal.com/reports/digital-2019-indonesia, diakses pada $19 / 4 / 2019$.

Ghozali, Iman. 2011. Aplikasi Analisis Multivariate dengan Program SPSS. Semarang: Badan Penerbit Universitas Diponegoro.

Law, rob \& Leung, Rosanna \& Lo, Ada \& Leung, Daniel \& Hoc Nang Fong, Lawrence. (2015). Distribution Channel in Hospitality and Tourism: Revisiting Disintermediation from the Perspectives of Hotels and Travel Agencies. International Journal of Contemporary Hospitality Management. 27. 431-452. 10.1108/IJCHM-11-2013-0498.

Lieber, E., \& Syverson, C. (2012). Online versus offline competition. In The Oxford handbook of the digital economy (p. 189). Oxford University Press Oxford, UK. 
Liu, J. N., \& Zhang, E. Y. (2014). An investigation of factors affecting customer selection of online hotel booking channels. International Journal of Hospitality Management, 39, 71-83.

Masiero, L., \& Law, R. (2016). Comparing reservation channels for hotel rooms: A behavioral perspective. Journal of travel \& tourism marketing, 33(1), 1-13.

Mun, W., \& Hall, M. J. (2008). Pricing consistency across direct and indirect distribution channels in South West UK hotels. Journal of Vacation Marketing, 14(4), 331-344.

Ong, B. S. (2012). The perceived influence of user reviews in the hospitality industry. Journal of Hospitality Marketing \& Management, 21(5), 463-485

Pitana, I. G., \& Pitanatri P.D.S (2016). Digital marketing in tourism: the more global, the more personal. In International Tourism Conference: Promoting Cultural and Heritage Tourism. Udayana University, Bali (pp. 1-3)

Pitanatri, P. D. S., \& Pitana, I. G. (2019). Challenging the Giants: Factors Contributing to Local Homestay Competitiveness in Ubud Bali. The Journal of Social Sciences Research, 5(3), 796802 .

Riduwan. 2011. Dasar - dasar Statistika. Bandung: Alfabeta.

Santoro, G. (2015). Evaluating performance in the hotel industry: An empirical analysis of Piedmont.

Scaglione, M., Schegg, R., \& Murphy, J. (2009). Website adoption and sales performance in Valais' hospitality industry. Technovation, 29(9), 625-631.

Schwartz, Z., Altin, M., \& Singal, M. (2017). Performance measures for strategic revenue management: RevPAR versus GOPPAR. Journal of Revenue and Pricing Management, 16(4), 357-375.

Silalahi, Ulber. 2006. Metode Penelitian Sosial. Bandung: Unpar Press.

Steed, E., \& Gu, Z. (2009). Hotel management company forecasting and budgeting practices: a survey-based analysis. International Journal of Contemporary Hospitality Management, 21(6), 676-697.

Tuominen, P. (2011). The influence of TripAdvisor consumer-generated travel reviews on hotel performance.

Yoeti, Oka A. 2003. Manajemen Pemasaran Hotel. Jakarta: PT Perca. 